Paper Title:

Author:

Position:

Contributing Author:

Position:

Contact Information:
Architecture in Mission Integration, Choreographing Constraints

\author{
Rod Jones \\ International Space Station Launch Package Manager \\ Steve Huning \\ International Space Station Launch Package Engineer
}

\author{
Mail Code OC2 \\ Johnson Space Center \\ Houston, Texas 77058
}

Work phone: 281-244-7941

Fax: 281-244-8193

\title{
Abstract: Architecture in Mission Integration, Choreographing Constraints
}

In any building project the Architect's role and skill is to balance the client's requirements with the available technology, a site and budget. Time, place and resources set the boundaries and constraints of the project. If these boundaries are correctly understood and respected by the Architect they can be choreographed into producing a facility that abides by those constraints and successfully meets the clients needs.

The design and assembly of large scale space facilities whether in orbit around or on the surface of a planet require and employs these same skills. In this case the site is the International Space Station (ISS) which operates at a nominal rendezvous altitude of 220 nautical miles. With supplies to support a 7 day mission the Shuttle nominally has a cargo capacity of 35,000 pounds to that altitude. Through the Mission Integration process the Launch Package Management Team choreographs the constraints of ascent performance, hardware design, cargo, rendezvous, mission duration and assembly time in order to meet the mission objective. 